\title{
A CONTRIBUIÇÃO DA LEGISLAÇÃO EDUCACIONAL BRASILEIRA PARA EVIDENCIAR O NEGRO COMO AGENTE ATIVO
}

\author{
Tatiane Araujo Santana ${ }^{1}$ \\ Telma Regina dos Reis de Assis ${ }^{2}$ \\ Zoraide Silva dos Santos ${ }^{3}$
}

\begin{abstract}
Resumo
Esta pesquisa tem como objetivo discutir a contribuição da legislação educacional brasileira para a sensibilização e valorização sobre o negro como agente ativo bem como reconhecer a diversidade cultural e valorizar a importância do negro, sua cultura e história percebendo suas memórias. Embora existam mudanças significativas ainda pode-se perceber que o negro ainda é símbolo de frustrações, inferioridade e violência fortalecendo ainda mais a tendência racista. A metodologia usada foi a pesquisa bibliográfica em livros, artigos e revistas. Conclui-se que faz-se necessário considerar a presença do povo negro na construção da população brasileira além de ressaltar as suas lutas mais presentes, a fim de minimizar os preconceitos empregados aos negros.
\end{abstract}

Palavras Chaves: Negro; Educação; Legislação Educacional

\begin{abstract}
This research aims to discuss the contribution of Brazilian educational legislation for raising awareness and appreciation of black people as an active agent as well as recognizing cultural diversity and valuing the importance of black people, their culture and history, realizing their memories. Although there are significant changes, it can still be seen that the black is still a symbol of frustrations, inferiority and violence, further strengthening the racist tendency. The methodology used was bibliographic research in books, articles and magazines. We conclude that it is necessary to consider the presence of the black people in the construction of the Brazilian population, in addition to highlighting their most present struggles, in order to minimize the prejudices applied to blacks.
\end{abstract}

Key words: Black; Education; Educational Legislation

\section{Introdução}

Esta pesquisa surge com a finalidade de abordar a importância da legislação educacional brasileira para a valorização da história e cultura afro-brasileira bem como

\footnotetext{
${ }^{1}$ Mestra em Ciências da Educação pela Faculdade Interamericana de Ciências Sociais - FICS. Tecnologia em Radiologia pela UNIRB. Docente pela UNIME/ UNIDAS EFIB. E-mail tatiane.conta123@gmail.com

2 Doutoranda em Ciências da Educação pela Faculdade Interamericana de Ciências Sociales (FICS). Mestre em Ciências da Educação pela Faculdade Interamericana de Ciências Sociales (FICS). Especialista em Metodologia e Didática do Ensino Superior pela Faculdade Católica de Ciências Econômicas da Bahia (FACCEBA). Licenciada em Pedagogia Plena pela Faculdade Regional de Filosofia, Ciências e Letras de Candeias (FAC). Licenciada em Matemática pela Universidade Salvador (UNIFACS). Docente pela Secretaria Estadual de Educação de Salvador Ba.Email:telmaassis@rocketmail.com

${ }^{3}$ Mestra em Ciências da Educação pela Faculdade Interamericana de Ciências Sociais - FICS. Especialista em Metodologia do Ensino Superior - UNITER. Especialista em Imaginologia com ênfase em Tomografia Computadorizada e Ressonância Magnética - FAVENI. Tecnóloga em Radiologia UNIRB. Técnica em Radiologia e Diagnóstico por Imagem-INSSJT. Email: zoraidessantos@hotmail.com
} 
a contribuição do sistema educativo para a sensibilização do respeito a diversidade do povo brasileiro através da conscientização que vivemos em uma sociedade de classes. Na escola os docentes podem trabalhar divulgando e valorizando a cultura africana e realizando discussões e debates sobre a cultura africana não apenas em datas pontuais.

E dentre os mais variados recursos pedagógicos pode-se destacar projetos, oficinas, livro didático entre outros no qual se pode reconhecer a possibilidade do processo de transformação de representações e reflexões sobre a cultura, pois:

O ambiente escolar é um local que exerce influência intelectual e cidadã sobre um indivíduo, vindo a afetar a formação da identidade dos alunos. Identidade a qual é definida pelos comportamentos, atitudes e costumes de um indivíduo e se modifica com a convivência entre sujeitos, ou seja, se constrói tendo o outro como referência (GOMES, 1996, [s/p]).

$\mathrm{Na}$ escola pode ser promovido o conhecimento e a valorização da história dos povos africanos e da cultura afro-brasileira na construção histórica e cultural brasileira Investir em estudos sobre a referida cultura nos ambientes escolares propõe aos educandos a valorização da oralidade, da corporeidade e da arte, por exemplo, a dança, marcas da cultura de raiz africana, ao lado da escrita e da leitura.

A história da população negra brasileira precisa ser resgatada, debatida e recontada novamente, pois a história que aprendemos é carregada de discriminação e preconceitos.

\section{A Discriminação e Inferiorizarão do Negro}

O processo de imigração, que se iniciou antes da abolição e tornou-se intenso depois dela, tinha como objetivo impedir a entrada do negro no mercado de trabalho, consequentemente impedindo a sua estabilidade civil, econômica e a sua condição de cidadão. Aos senhores alegavam incompetência dos negros para exercer determinadas funções que tinham maior valor social, limitando essas funções para serem executadas pelos emigrantes brancos, a fim de que os mesmos pudessem miscigenar o País. Ao abordar sobre a discriminação dos negros ressalta-se que:

O povo negro era degenerado devido a influências desfavoráveis externas, sendo necessários séculos de desenvolvimento para superar a degeneração resultante. A conversão dos negros ao cristianismo não faria com que as características morais (que são transmitidas geneticamente) mudem, pois, o negro convertido rebaixa invariável e necessariamente a nova religião ao nível de sua própria cultura mental (RODRIGUES, 1935, p. 394). 
O autor aborda que o negro teve progressos pelo seu convívio com as raças dito superiores, embora continue sendo culturalmente inferior. $O$ processo de miscigenação fracassou, pois, a união de mestiços de pele clara com negros resulta em descendentes mais claros. Essa mistura trouxe para muitos mestiços a falta de uma identidade e de um reconhecimento para com a sua cor e os seus ancestrais. E neste momento chegam os imigrantes europeus. Com o objetivo de superar esses entraves, "era preciso seguir os passos da parte da humanidade branca, tida como mais civilizada, e, se fosse possível, importar um pouco da própria Europa através do incentivo à imigração" (VAINFAS, 2002, p. 142).

O estímulo à imigração europeia prejudicou a chance dos negros usufruírem da democracia, diminuindo, consequentemente a chance dos mesmos de participarem da política do País. A classe dominante, a teoria cientifica tenta internalizar no próprio negro e na sociedade através de teorias cientificas da época que a raça branca é o modelo de perfeição e:

A utilização do imigrante europeu foi uma saída direcionada para a
substituição do braço escravo nas regiões cafeeiras, não é menos verdade
que em outras províncias, as expectativas teriam se voltado para a promoção
do 'progresso' agrícola, social e cultural através da formação de núcleos
coloniais (RODRIGUES, 1935, p. 394).

O branqueamento do País tem o objetivo de divulgar o Brasil onde não apresenta diferentes grupos raciais, e sim uma nação branca que pela miscigenação irá erradicar o negro da população, como se isto fosse um objetivo velado na sociedade como um todo. Essa política se consolida mediante a maneira pela qual o negro vem sendo mostrado ao longo da história, de forma estereotipada ou inferior.

A UNESCO patrocinou uma investigação sobre a democracia racial no Brasil após a Segunda Guerra mundial, ao mesmo tempo foram realizados congressos de intelectuais e militantes antirracistas sobre o negro. Essas duas ações chegaram à conclusão que: existem preconceito e racismo no Brasil (CHALOUB. S. 1990).

O país participou da III Conferência Mundial de combate ao racismo e firmou compromisso mundial de acabar com essas práticas dentro do seu território, assumindo uma postura de negação do reconhecimento de uma democracia racial que o Brasil tinha, a disseminação de informações é responsabilidade dos livros didáticos, onde o negro é marginalizado na sociedade, pois a sua aparição vem da política do branqueamento. A representação da educação não consegue levar a percepção dos negros nos livros, pois eles não se percebem representados. 
Na história do Brasil é possível constatar vários momentos em que foi negado aos negros o direito á educação, sistema educacional por muito tempo reproduziu um modelo de educação que não era nosso, o modelo eurocêntrico. No Decreto ํㅜ 7.031$A$, foi estabelecido aos negros o período noturno para os estudos, decreto este que se tornou mais uma estratégia impedindo o acesso dos negros à escola (SANTANA e MORAES, 2010).

Questionava-se que condição o negro tinha para aprender depois de um dia exaustivo de trabalho e sem contar que com os pés descalços não poderiam assistir as aulas, mas que condições financeiras eles tinham para pode comprar calçados. As exigências revelavam a impossibilidade da aplicabilidade desse decreto depois de séculos de negação da cultura e das contribuições dos negros/as para o desenvolvimento do Brasil, e:

Em 9 de janeiro de 2003, foi aprovada a Lei 10.639/2003, que altera a Lei $n^{\circ}$ 9.394, de 20 de dezembro de 1996, que estabelece as diretrizes e bases da educação nacional, para incluir no currículo oficial da Rede de Ensino a obrigatoriedade da temática 'História e Cultura Afro-brasileira', e dá outras providências (BRASIL, 2004, [s/p]).

A lei 10.630/2003 implica em mudanças para educação, mudanças essas que dê primazia ao conceito afro-brasileiro e africano. Esta política pública contribui para o processo de formação de identidade e autoestima, tanto dos/as negros/as quanto dos/as não negros/as, uma vez que essa lei, não diz respeito apenas à população negra, mas a todos os brasileiros.

\section{A Importância da Divulgação da Cultura Negra Além do dia 20 de Novembro}

A batalha pela consideração, decência e plenos direitos da cidadania para as pessoas negras no Brasil já tem um longo caminho histórica. Resguardar a memória é uma das formas de construir a história. É pela disputa dessa memória, dessa história que nos últimos anos se comemora no dia 20 de novembro, o "Dia da Consciência Negra". Nessa data, em 1695, foi assassinado Zumbi, um dos últimos líderes do Quilombo dos Palmares, que se transformou em um grande ícone da resistência negra ao escravismo e da luta pela liberdade.

A cada ano que passa, essa data tem sido reconhecida e relembrada com mais intensidade; e não apenas no dia 20 , mas durante todo o mês de novembro, acontecem, em todo o País, diversas celebrações, manifestações e momentos de resgate da história da cultura afro, escolas, universidades, igrejas, comunidades, aos 
poucos começam a aderir a essa "nova consciência", e novos espaços estão sendo abertos para uma reflexão afirmativa sobre esse tema.

A diversidade de formas de celebrações do 20 de novembro, também chamada de "Semana da Consciência Negra", permite ter uma dimensão de como essa data tem propiciado congregar os mais diferentes grupos sociais e:

Os adeptos das diferentes religiões manifestam-se segundo a leitura de sua cultura, para dali tirar elementos de rejeição à situação em que se encontra grande parte da população afro-descendentes. Os acadêmicos e os militantes celebram através dos instrumentos clássicos de divulgação de idéias: simpósios, palestras, congressos e encontros; ou ainda a partir de feiras de artesanatos, livros, ou outras modalidades de expressão cultural (ANDRELINO CAMPOS, 2011, p.57).

Ainda nesse sentido, faz-se necessário que se conquiste o "Dia da Consciência Negra" como o dia nacional de todos os brasileiros e brasileiras que lutam por uma sociedade democrática e igualitária, unindo toda a classe trabalhadora num projeto de nação que contemple a diversidade engendrada no nosso processo histórico.

Em todos os grupos humanos, é possível observar a utilização de meios pedagógicos como formas de transmissão do saber, por meio dos quais os sujeitos compartilham conhecimentos, símbolos e valores. Em sociedades "modernas", criouse uma sistematização desse saber, nas quais mediante modelos formais e centralizados as informações são transmitidas. Acreditava-se que essa seria a forma viável de adquirir polidez e promover um desenvolvimento mais especializado.

Esse lócus de conhecimento foi denominado Escola, constituindo-se num sistema aberto que passou a fazer parte da superestrutura social formada por diversas instituições como: família, igreja, meios de comunicação. O sistema escolar é organizado para cumprir uma função social que, em geral, está de acordo com as demandas sociais.

Assim, a escola é lugar privilegiado para que se estabeleça um diálogo sério e respeitoso entre as distintas culturas presentes na sociedade. Enquanto tal diálogo não ocorrer, enquanto forem valorizados alguns grupos e classes e outros, a maioria, forem abafados, explorados, não conseguiremos construir a nação brasileira democrática e livre. Combater o racismo e toda sorte de discriminação requer de cada pessoa consciência dos conceitos que perpassam as ações, ideias, propostas,

Para tanto, há que se buscar compreender o que é ser negro no Brasil, partindo do que se vê na escola. Daí a importância de abordar sobre cultura africana da no âmbito escolar. Com o propósito de respeitar as diferenças, sejam elas religiosas, 
culturais, étnicas ou raciais. Tal ação apresenta-se como fundamental para a construção de uma sociedade justa e igualitária. A diversidade étnico-racial é uma das grandes riquezas brasileiras e precisa ser preservada e valorizada.

É fato público e notório que a raça negra enfrenta dificuldades enormes para ter uma vida digna em nosso país, em que pese sua contribuição histórica para construção e o progresso do Brasil. O racismo, o preconceito e a discriminação contra os negros ainda são muito fortes, de modo que o próprio IBGE (Instituto Brasileiro de Geografia e Estatística) mostra, de forma clara, que esta parcela da população brasileira é prejudicada no que se refere à inclusão nos direitos gerais da sociedade, em tese, garantidos, a todos, pela Constituição, pois:

É sabido que o Brasil foi erguido a partir das forças do trabalho escravo. Mesmo com o 'fim da escravidão' os problemas do negro no país na acabaram. Os negros ainda hoje são discriminados, vive a maioria nas favelas, marginalizados, trabalham nos considerados piores empregos, a grande maioria são analfabetos ou semi-analfabetos (OLIVEIRA, 2010, pg.59).

É inegável a contribuição que os negros africanos deram para a nossa cultura, seja na língua, na dança, na culinária, na música etc. Assim, a necessidade de reconhecer o papel do negro na formação da cultura e das riquezas do Brasil se faz premente.

Diante do exposto é conveniente realizar reflexões e discussões que promovam a conscientização dos alunos em relação à contribuição dos africanos para a cultura brasileira, levantando desta forma a sua auto-estima e despertando o interesse em conhecer mais detalhadamente sobre esse povo com objetivos de:

$>$ Promover a cultura negra dando ênfase à semana da consciência negra, oportunizando aos alunos uma releitura acerca da temática de modo a estimulá-los e uma reflexão significativa e substancial bem como levantar a auto-estima dos mesmos.

$>$ Enfatizar a presença negra no Brasil, resgatando sua história;

$>$ Discutir a adoção de políticas afirmativas, que pretendam a inclusão dos negros aos direitos gerais da sociedade;

$>$ Identificar as diversas contribuições dos negros para a economia brasileira;

> Investigar sobre a vida e as atitudes de Zumbi dos Palmares;

> Analisar a importância da Lei 10.639/03 para a educação no Brasil. 
A relevância do estudo de temas decorrentes da história e cultura afro-brasileira e africana não se restringe à população negra, ao contrário, diz respeito a todos os brasileiros, ema vez que devem educar-se enquanto cidadãos atuantes no seio de uma sociedade multicultural e pluriétnica, capazes de construir uma nação democrática.

\section{A Lei 10.639/2003}

$\mathrm{Na}$ metade do século $\mathrm{XX}$, o movimento social negro que buscava reconhecimento das matrizes africanas na formação da cultura brasileira, passa a expressar suas reivindicações através de pressão política. Na Convenção Nacional do negro realizada no Rio de Janeiro e em São Paulo, intelectuais e ativistas afrodescendentes, lançaram medidas afirmativas a favor do legado da população negra, através, nasce à necessidade de se legitimar uma Lei que torne obrigatório o estudo das raízes africanas. Esta inclusão nos currículos da educação básica amplia 0:

Foco dos currículos escolares para a diversidade cultural, racial, social e econômica brasileira. Mostraremos que este momento é de relevância não apenas para a população negra, mas também a todos os brasileiros, uma vez que devem educar-se enquanto cidadãos atuantes no seio da sociedade multicultural e pluriétnica, sendo capazes de construir uma nação democrática (BORGES, 2010, p. 18).

Esta inclusão refere-se a um momento em que a educação brasileira procura resgatar e estimar devidamente a história e a cultura do povo afrodescendente e indígena, procurando assim minimizar os prejuízos, que se ecoavam muitos séculos, à sua identidade e a seus direitos. A sociedade excluída privilegia as culturas oficiais e valores do cotidiano e renega suas origens e valores. Para os valores europeus os rituais pedagógicos estão acima dos outros grupos étnico-raciais.

O movimento negro aponta a importância de direcionar projetos que valorizem a história e cultura dos afro-brasileiros comprometendo de forma positiva as relações étnico-raciais, valorizando a cultura e autonomia dos indivíduos. Os espaços educativos contribuíram na valorização das diversidades culturais do nosso país, modificando a visão dos conteúdos estudados em sala de aula.

Os Parâmetros Curriculares Nacional foram criados com o objetivo de reconhecer, valorizar, divulgar e respeitar a história de resistência dos negros africanos escravizados no Brasil e: 
A obrigatoriedade de inclusão de História e Cultura afro-brasileira e africana nos currículos da educação básica é um momento histórico que objetiva não apenas mudar um foco etnocêntrico, marcadamente de raiz europeia para um africano, mas sim ampliar o foco dos currículos escolares para a diversidade cultural, racial, social e econômica brasileira (BORGES., 2017, p. 72).

A nova Lei coloca a sociedade diante da responsabilidade de assumir a história do povo africano estabelecendo a obrigatoriedade em todas as redes de ensino, público e particular o estudo da temática "história e cultura afro-brasileira" na educação nacional, determinando uma revisão do currículo, adequando as novas exigências e:

Quando se pensou em criar uma lei que garantisse a preservação da cultura afro-brasileira, por meio do ensino obrigatório nos estabelecimentos oficiais de educação básica, não houve um esforço mais amplo em relação à preparação técnica do Professor, para lidar com essa problemática, nem muito menos com suas variáveis (CÉLIA DA SILVA, 2001, p. 66).

É preciso começar a preparar os professores para entenderem a verdadeira história povo negro e escravizados e sua grande contribuição no processo de construção de nosso País, os projetos pedagógicos devem ser muito bem estudados e executados, assim estes docentes estarão aptos para incorporarem em suas salas de aulas estudos da cultura afro, pois muito deles não estão preparados para lecionarem a respeito da cultura africana. Aos sistemas de ensino em geral compete:

Ampliar, criar projetos, ações e implementar currículos voltados para educação racial e investir na formação continuada dos seus professores. $O$ trabalho da escola, e empenho dos profissionais da educação é de extrema importância para que possa colocar em prática a Lei (SILVA, 2012, p. 29).

O Ministério da Educação (MEC) lançou nestes últimos anos, livros e conteúdos voltados para pesquisadores, professores e estudantes afim de estudos que auxiliem na disseminação das informações da cultura negra e da Lei 10.693. Passaram alguns anos, após a promulgação dessa lei e ainda permanece o desafio das escolas, professores, livros didáticos de colocá-la em prática de maneira eficaz e correta, desprezando totalmente ideias e atitudes racistas que venham a prejudicar a imagem do negro na nossa sociedade.

O ensino da história e cultura afro-brasileira e africana no Brasil sempre foi lembrado nas aulas de História com o tema da escravidão negra africana. O escravo é uma condição inerente aos seres humanos além de trazer a ideia de que ser escravo. Quando se refere na sala de aula, ao escravo africano, acontecem equívocos, pois ninguém é escravo - as pessoas foram e são escravizadas (MATTOS, 2013). 
Os docentes devem apresentar a cultura afro-brasileira como formadora da sociedade, onde os negros são partes da história, dando o devido valor aos intelectuais negros brasileiros, a cultura, a música, a culinária as matrizes africanas.

Também nesta lei foi instituído o dia Nacional da Consciência Negra no dia da morte de Zumbi dos Palmares, líder quilombola negro, marcado pela luta contra o racismo no Brasil, dia 20 de novembro.

O fato dos livros didáticos utilizados retratarem o negro estigmatizado origina danos ao aluno, que acha normal o racismo e a discriminação contra as pessoas negras, reforçando-se, então, ideias racistas dentro e fora da escola, pois:

\begin{abstract}
A invisibilização do negro no livro didático trabalhado pode constituir um desconhecimento de questões relativas á participação dos negros no produto social, com reivindicações ativas por melhorias no bem-estar social por sofrerem com a perversidade do racismo (JESUS, 2012, p. 24).
\end{abstract}

Com o surgimento de movimentos sociais, especialmente o do movimento negro nos anos 1980, além de denunciar e da reinterpretação da realidade social e racial brasileira, a reeducação da população, dos meios políticos e acadêmicos e do Projeto Nacional do Livro Didático (PNLD) em 1996, o interesse pelo tratamento diferenciado aos negros, passou a ganhar mais adeptos.

O PNLD passou a proibir a circulação de livros didáticos que expressem preconceitos de origem, de cor, de etnia, de gênero e qualquer outra forma de discriminação. Com a aprovação da Lei Federal no 10639/2003, que torna obrigatório o ensino de História e Cultura Afro-Brasileira e Africana em todas as disciplinas do currículo escolar, nas disciplinas de Educação Artística, Literatura e História.

\title{
A Base Nacional Comum Curricular (BNCC) e o ensino sobre História da África e cultura afro-brasileira e africana
}

Na pratica pedagógica dos professores no cotidiano, em sala de aula, é comum alguns alunos ter a ideia que o ensino de História pressuponhe meramente uma disciplina que somente serve para memorização de fatos e acontecimentos que não se conectam com a visão de mundo e, enfim, a visão que se tem do mundo. Esta ideia possibilita que o ensino de História em algumas redes de ensino esteja distante da realidade dos alunos estes, não se identificam com o conteúdo sugerido pelo professor. Uma vez que a resistência no ensino pode ser um fator presente, por sua vez, acarreta uma dualidade do conteúdo proposto pelo professor e da assimilação do mesmo, pelos alunos. 
Diante dessas circunstâncias, as discussões sobre o ensino de História possibilita uma reflexão da situação da realidade de muitas redes de ensino em relação a não identificação dos alunos com os conteúdos ministrados pelos professores no dia a dia, em sala de aula, deste modo, causaram em algumas situações no ambiente de ensino problemas de diálogos entre o professor e aluno, afetando o processo ensino e aprendizagem deste última e, consequentemente, a apreensão do conhecimento, pois, para o mesmo, este ensino não tinha utilidade.

Do mesmo modo, a suposta "inutilidade" da História, partilhada em alguma medida por alunos e professores, tem aberto precedentes para que o seu lugar nos currículos escolares venha a ser constantemente questionados. De tal modo, entre a década de 80 e 90 o ensino de História começou a ganhar mais notoriedade das correntes historiográficas, tanto na Academia quanto nas reformas curriculares, que colocaram em evidência novos temas e novos objetos para o conhecimento histórico.

Igualmente, os conteúdos começaram a se adaptar, dando outros contornos tanto no ponto de vista do contexto das relações sociais existentes no cotidiano e quanto nas dimensões socioculturais, presentes no imaginário coletivo, e, principalmente, na vida privada dos sujeitos. Diante deste cenário, o ensino de História em especial, a luta pelo seu reconhecimento da disciplina foi um processo de altos e baixos, pois:

\begin{abstract}
A História não é uma memória atávica ou uma tradição coletiva. É o que aprendemos de nossos professores, de autores de livros didáticos de história e dos editores de artigos em revistas e programas de televisão. É muito importante que os historiadores lembrem-se da responsabilidade que eles têm e que consiste, antes de tudo, manter-se aparte das paixões da política ainda que as compartam. Afinal, também somos seres humanos (HOBSBAWM, 2008, p. 38).
\end{abstract}

A disciplina de História fomenta em uma área do conhecimento que caracteriza de uma reflexão temporal e espacial e, consequentemente, uma análise do contexto humano das relações sociais. A importância dessa reflexão e porventura a análise possibilita que os (as) professores (as) de História atentem a compreender durante as suas práticas, práxis e ações pedagógicas uma melhor assimilação do fato histórico do passado, ou seja, algo que ainda está inacabado e o presente na intenção de compreender nas suas rotinas pedagógicas no ensino de História para entendermos o atual presente: seja nas memorias, seja nos acontecimentos, seja nas fontes documentais, seja nas narrativas, seja nas interpretações dos fatos históricos, sejam 
compreensões globais e, consequentemente, particulares sobre as realidades históricas.

Ao mesmo tempo em que é necessário quebrar o paradigma de que a História é a ciência que estuda apenas fatos passados, personagens heroicos, datas, utilizando como método central a memorização. Nesse sentido, é importante o professor levar aos alunos a desenvolver e estimular o conhecimento instigando e intrigando seu pensamento complexo a fim de levá-los a compreensão da realidade para intervir nela e transformá-la e, por conseguinte, os mesmos, possam diferenciar o sentido e o papel das diferentes fontes de conhecimento. A esse respeito ressaltase que:

Devemos nos congratular com todos os que individual ou coletivamente contribuíram e tem contribuído para a melhoria do ensino de História em todos os níveis. No entanto, no que se refere a pratica cotidiana do professor de $1^{\circ}$ e $2^{\circ}$ graus, isto é, àquela instância denominada de sala de aula, de um modo geral as mudanças ainda não são satisfatórias (SCHMIDT, 2002, p.55).

Por outro lado, apesar dos fatores positivos em relação ao ensino de História, o pensamento de Schmidt atenta o preocupante distanciamento do ensino de História, no Ensino Fundamental, Ensino Médio. O que se pode pressupor que os anos iniciais e finais o que se leva em conta uma mera representação do conhecimento produzido pelas universidades. Justamente, a não produção de seres questionadores e pensantes nas redes de ensino. Nessa visão:

\begin{abstract}
Se aceitamos então essa dissociação referida acima entre a ciência e o social, sem a devida perspectiva crítica, estamos assumindo na prática um modo de pensar a nossa disciplina, a História, e o seu ensino e a pesquisa, dentro de um esquema tradicional, onde a Universidade é sempre pensada como centro de produção do saber, ou como diria Michel Certeau, ela se transforma no "lugar social" de onde falam os cientistas. E assim a ciência que se produz neste espaço social está circunscrita a ele, começa e acaba nele, produzida, consumida e criticada, revista e analisada dentro de um círculo cada vez mais fechado que lhe determina o permitido e o interdito (FENELON, 1982, p. 25-26).
\end{abstract}

Ao mesmo tempo, o distanciamento do ensino de história na Educação Básica entre a universidade aponta que:

A expressão ensino superior também produz, em contrapartida (=equivalência), não a sua complementação, mas o seu contrário: existe um ensino inferior. Sendo o ensino do terceiro grau o superior, os níveis anteriores são, portanto, inferiores... Mas, inferior/superior em relação a quê? Essa hierarquização - perigosa e elitista, além de imobilizadora - atribui funções e papéis específicos e extremamente diferenciados a cada um dos níveis de escolaridade: ao ensino universitário (o superior...) compete produzir conhecimentos para consumo do ensino inferior (MICELI, 2000, p. 104-105). 
Em meio às disparidades em questão do ensino, os desafios no cotidiano dos (as) professores (as) do ensino de História têm representado esforços contínuos, no sentido de alcançar êxito profissional, obrigando-os a modificar seu trabalho em função de cada mudança na Educação Básica, Ensino Fundamental e Ensino Médio.

As proposições da LDB, reafirmadas na Resolução n. 1/99 do CNE, indicaram um novo momento nas perspectivas sobre a formação de professores, tanto na estrutura curricular, como na articulação formativa dos currículos e ainda na preocupação com a qualificação dos formadores de formadores, dos professores da Educação Básica.

Além disso, para as Universidades, a formação científica sempre foi uma exigência, concretizada por meio das pesquisas propostas nos currículos de formação docente. De tal modo é que tem abertura a luta de completo o conjunto de educadores para substituir a Lei no 5.540/68, que meditava a respeito da Reforma Universitária, e a Lei de Diretrizes e Bases da Educação (LDB) de número 5.692/71. Sobre o tema tratado:

Todos os setores sociais, da direita à esquerda, das instâncias do MEC aos organismos representativos da sociedade civil e política, participaram do processo de elaboração da LDB da Câmara, de 1988 a 1993, através de audiências públicas, seminários temáticos e negociações políticas. (MURANAKA e MINTO 1998, p. 74).

Conforme a nova Lei de Diretrizes e Bases da Educação - LDB, de o 9.394, sancionada pelo presidente Fernando Henrique Cardoso em 20 de dezembro de 1996. Estabeleceu-se como instrumento legal de gerenciamento do sistema educacional brasileiro. Doravante, por outro lado, a execução da nova LDB atende basicamente aos interesses da sociedade internacional. De fato, deixa evidente o favorecimento dos países mais abastecidos economicamente e politicamente.

Em consequência, alterou e de certo modo, afetou a educação brasileira, constituindo uma insatisfação entre os profissionais de educação em especial, os profissionais de História, no exato momento da consolidação do currículo, pois:

\footnotetext{
Estamos assistindo a uma retomada da centralização da educação que alija da discussão os seus principais sujeitos: alunos (as) e professor (a) es novamente vistos como objetos incapacitados de construir sua história e de fazer, em cada momento de sua vida escolar, seu próprio saber. (BITTENCOURT, 2004, p. 40).
}

Por outro lado, na atualidade, a atuação pedagógica dos professores de História no contexto escolar tem sido seriamente criticada pelo fato dessas práticas 
não atenderem aos pressupostos referenciados na LDB. Na verdade, os Parâmetros Curriculares Nacionais (PCN) ${ }^{4}$, implantado em todo território nacional fomentou como uma espécie de revisão do ensino fundamental e médio, a fim de suscitar novos olhares, perspectivas e, consequentemente, novas discussões e reformulações sobre o ensino.

No ponto de vista do ensino de História, os referenciais curriculares influenciaram e promoveram implementações positivas e necessárias em relação à grade curricular, a práxis e a pratica pedagógica dos (as) professores (as) das redes ou instituições de ensino. Partindo desse princípio, os referenciais curriculares ajudaram gradualmente em associar e incorporar uma ação mais motivadora e, consequentemente, possibilitou condições para produção e profusão do conhecimento.

Uma prova disso, a primeira versão da Base Nacional Comum Curricular - BNCC em sua primeira intenção, implantado em todos Estados da Federação, questionou em um ambiente para discussões a respeito das realidades regionais, ocasionando um veículo de profusão e ao mesmo tempo, um meio pelo qual, questões como gênero, classe e raça apareceram de uma forma menos paragramática. Em particular, a partir dessas observações, apesar de todo cuidado em priorizar os conteúdos relativos à História da África e dos povos indígenas na América na BNCC, pressuponhe ocasionar uma dualidade destes conteúdos teóricos como o prático. Tal perspectiva nos aponta a ausência de protagonismo. Outro aspecto a considerar é que:

\begin{abstract}
Essas lógicas não são meros recipientes de conteúdos, mas atribuem significados ao processo histórico, pelos mecanismos de funcionamento do currículo oculto. Por exemplo, posso ensinar o valor da cultura nacional através de músicas, mas se todas elas forem cantadas em inglês, transmitese implicitamente um sentido de valorização de uma cultura estrangeira, embora tudo o que eu digo vá no sentido contrário. Da mesma forma, posso afirmar à exaustão que o importante não é a memorização, mas a compreensão dos conteúdos históricos. Porém, se a lógica de seleção e articulação dos conteúdos históricos for linear e tradicional, querendo ensinar um pouco de tudo o que há para saber sobre o passado, mesmo não tendo significado nenhum para o alunado, apenas porque é difusamente reconhecido como 'importante', acabo transmitindo uma ideia de conhecimento histórico contrária àquela que enuncio explicitamente. Ainda nesse mesmo raciocínio, não é a inclusão de elementos de História da China que torna a "História da Civilização" vacinada contra o eurocentrismo (CERRI, 2009, p.144).
\end{abstract}

\footnotetext{
${ }^{4}$ Parâmetros Curriculares Nacionais criados pelo Governo Federal, através do Ministério de Educação - MEC.
} 
Os fundamentos expressos no currículo oficial para o ensino de História hoje, infelizmente, continuam sobre um mundo social que não existe mais. Justamente, o que podemos perceber que a primeira versão da BNCC comparada como a nova versão da BNCC caracteriza o não protagonismo relativo à História da África e dos povos indígenas. Nesse sentido, o currículo de História é centrado numa perspectiva do padrão europeu apesar de tentativas de torna-los e transformá-los em pluriculturais.

Diante do que foi exposto, o ensino de História alinhado à BNCC na atualidade, contemplam dois pontos importantes:

1) Os alunos possam absorver o aprendizado associando os acontecimentos do presente e do passado a fim de desenvolver uma visão crítica e questionadora e, por último

2) Associar estes acontecimentos com a realidade ou com o seu contexto.

De modo especial, a BNCC analisando a priori é um modelo que tenta atingir um ensino mais realista, coerente e consciente. De fato, a mudança pressuponhe no papel do aluno no processo ensino e aprendizagem. Ora, deixar de ser um mero reprodutor do conhecimento e adotar um papel de questionador do mesmo. Com a BNCC ganha notoriedade de traçar os paralelos entre os fatos históricos e a realidade, ou seja, distinção de ambos. Sem dúvida, a BNCC nos ajuda a pensar e refletir sobre o ensino de História a partir de questões que são colocadas e inseridas no presente para refletimos e inquietarmos com o passado.

A partir do momento em que as questões da cultura, das heranças, da tradição africana e afro-brasileira forem contempladas para cada sala de aula, enquanto ciência, enquanto conhecimento científico, a estima da nossa população se elevará. A partir daí, deslanchará o interesse pelo estudo da sua própria história.

O interesse do aluno em se sentir gente, se sentir sujeito dessa história, sujeito nesse país. Porque até então, até mesmo os livros didáticos, nos colocam como apêndice da própria história. É como se esse país só passasse a existir a partir da ação colonizadora da exploração dos colonizadores.

Os alunos não têm motivação para entrar numa sala de aula, porque em toda a cultura que ele pratica cá fora - ele toca um tambor, ele come uma comida afro, ele dança a dança afro - ele é negro. Mas, ao adentrar na escola, ele se torna uma pessoa branca. Tudo o que é "jogado" nele é que a cultura branca é a correta. Ele não tem 
história, fica invisível nesses currículos que são impostos nas nossas escolas. Ele se sente invisibilizado. Quando ele se descobrir, vão ser fantásticos os resultados. Ele vai ter mais motivação, vai se sentir sujeito na história e o conhecimento e a aprendizagem se deslancharão.

A educação das relações raciais tem o potencial de qualificar a educação brasileira. Não se trata de apenas de cumprir uma normativa: ensinar história e cultura africana e afro-brasileira é situar o Continente Africano na escala mundial, fato que culminou na definição em 2015, pela ONU, da Década Internacional dos Afrodescendentes, com término previsto para 31 de dezembro de 2024 . Esta indicação coloca em relevo que, apesar dos esforços empreendidos pelos Estadosmembros, milhões de seres humanos seguem sendo vítimas do racismo, da discriminação racial, da xenofobia e de várias formas de intolerância. E isso precisa acabar (MURANAKA e MINTO, 1998).

Atualmente após a Lei 10.639/2003 ainda não se tem muitos gestos decisivos no âmbito dos governos que evidenciem decisão política de que ela será respeitada à altura do resgate que os negros merecem e exigem. Alega-se que não há na um número satisfatório de profissionais preparados em número suficiente para dar conta do recado - o que explicita o óbvio: a história de lutas de africanos e afrodescendentes, assim como a cultura negra não são vistas como suficientemente importantes pelo aparelho formador de professores e nem pelo professorado durante séculos, situação que desnuda racismo e indica que urge ampla mobilização e monitoramento para que ela pegue. O maior desafio a ser enfrentado após um ano de sua aprovação ainda é o de colocar essa inclusão em prática de maneira eficaz e adequada nas situações cotidianas da vida escolar de todo o território nacional.

\section{O Papel da Escola na Desconstrução do Preconceito}

A escola como instituição primordial, assume sua função na transformação social do indivíduo que por consequência garante o exercício da cidadania, do trabalho e sua continuidade ao longo dos tempos. Considerando que tal orientação pauta-se na Lei de Diretrizes de Bases $(\mathrm{LDB})^{5}$ e das Diretrizes Curriculares Nacionais (DCNs) ${ }^{6}$ para o Ensino no Brasil, que visa ampliar a cidadania como um dos objetivos

\footnotetext{
${ }^{5}$ Define e regulariza a organização da educação brasileira com base nos princípios presentes na Constituição.

${ }^{6}$ Normas obrigatórias para a Educação Básica que orientam o planejamento curricular das escolas e dos sistemas de ensino.
} 
principais que devem nortear o trabalho pedagógico, deste modo, a escola deve buscar o desenvolvimento de competências e habilidades que permitam a compreensão da sociedade.

Sendo ampliar a cidadania, um dos objetivos que devem permear o trabalho pedagógico, a escola deve proporcionar o desenvolvimento de competências e habilidades que permitam favorecer ao indivíduo experiências pertinentes ao convívio humano. Tais experiências devem ser entendidas como uma produção "dinâmica" dos seres humanos, assim como um processo permanente de construção e reconstrução, entendendo que a cidadania significa capacitar-se para saber avaliar os processos pertinentes a sociedade e o papel daqueles que o constitui.

\begin{abstract}
Ainda que a perspectiva e os procedimentos do professor possam ser considerados tradicionais, e inegável existência de certa coerência entre o conceito adotado de cidadania e a prática pedagógica. Uma vez que seu conceito informa uma concepção de cidadão ativo, capaz de situar-se diante de dificuldade, de formar opiniões próprias, de ler o mundo, de distinguir o "verdadeiro e o aparente", sua prática pedagógica não se encaminha para a transmissão de regras e para o condicionamento de comportamento, mais para a construção de competências e a habilidade que permitam ler o mundo e interpretá-lo (COELHO, 2008, p. 103).
\end{abstract}

Deste modo, é também no ambiente escolar que são apresentados um conjunto de debates voltados para as questões étnicas e raciais, que são eleitas para discussões em grupos de estudos que objetivam fomentar a criação de formações para a comunidade escolar, de modo que as possibilidades de aprofundamentos se estreitem para o aprofundamento das causas e consequências acerca da dispersão dos africanos pelo mundo. São apresentadas também abordagens sobre a História da África antes da escravidão, tendo como pertinência as contribuições dos afrodescendentes para o desenvolvimento da humanidade.

É fato que a questão racial, é uma abordagem de interesse coletivo e deve ser conduzida para a reeducação das relações entre descendentes, afro descentes de todo território nacional e internacional, que por consequência o reconhecimento dessas concepções, fortalece a necessidade de valorização e respeito mútuo, entendendo que o seu direto começa, quando o do outro termina.

Ao introduzir os conteúdos relativos à cultura afro brasileira e à historia da África, a Lei 10.638/03 desloca a perspectiva adotada, ate em tão, mas representação sobre o Brasil e sobre a sua formação, transformado em conteúdo didático. Tradicionalmente, o ensino brasileiro adota a formação brasileira como um desdobramento lógico e consequente da história europeia, ou seja, após rápida referência às sociedades antigas, como a egípcia e a mesopotâmica, os alunos aram levados a ver a sociedade 
ocidental, desde a conformação do mundo Greco-romano, na Europa como a matriz cultural brasileira (ROCHA, 2008, p.57).

Assim, de acordo com a Lei 10639/03, o ensino da História da África deve contribuir para a aquisição de conhecimentos, entendendo que as contribuições dos egípcios para o desenvolvimento da humanidade são marcas culturais da África e devem ser enfatizadas individualmente em Arte, Literatura e História do Brasil, de modo que os docentes valorizem a identidade negra para desconstruir o mito da democracia racial constituída dentro do âmbito escolar.

É imprescindível que esse tipo de discussão deve permear na escola nas serie iniciais da vida escolar, período em que a criança se encontra em processo de constituição de personalidade e o conhecimento nessa fase passa a ter uma particularidade significativa na formação, pois as observações acerca do tema propício uma cultura de valorização a diversidade e os conflitos podem ser resolvidos através da educação. O convívio com as diferenças faz parte do cotidiano dos indivíduos, pois se agregam na diversidade, considerando que os conhecimentos adquiridos se efetivam na desconstrução e combate do preconceito.

Desenvolver atividades pontuando as relações étnicos raciais perpassam questões de interesse, pois desde de 2003, com a aprovação da lei 10639, que determina a inserção de conteúdos de história e cultura afro-brasileira e africana nos currículos escolares. Nesse sentido com essa abordagem o combate na rotina escolar contribui-se para o combate ao racismo, valorizando diferenças e rompendo os preconceitos.

A compreensão histórica acerca da diversidade étnico-racial contribui para uma maior visibilidade na formação da sociedade brasileira, quando o processo de ensino aprendizado é inserido através de experiências raciais.

A falsa ideologia da harmonia racial é valorizada quando na sociedade são apresentadas as contribuições exclusivamente de pessoas brancas, sem reconhecimento e valorização dos diferentes contextos dos diversos grupos étnicos apresentados em nossa sociedade. Negros e índios possuem particularmente um marco importante na história e construção da sociedade brasileira, e isso precisa ser apresentado e evidenciado em nosso meio.

Estabelecer um diálogo vivenciando o racismo no cotidiano estrutura-se uma maneira de valorizar nos espaços escolares esse debate, que deve promover a compreensão e aceitação do outro, com suas diferenças e necessidades, por outro lado visa alertar a comunidade escolar para a necessidade de 
atuarmos, juntos, na construção de uma sociedade cada vez melhor (EDUCADOR 306, 2019, [s/p])

Para uma efetiva prática docente em sala de aula, atendendo as adversidades, aconselha-se aos profissionais de educação o conhecimento e aplicabilidade dos Parâmetros Curriculares Nacionais.

O conhecimento das Diretrizes Curriculares Nacionais para a Educação das Relações Étnico-Raciais para o Ensino da História e Cultura Afro-Brasileira e Africana é de fundamental importância para compreensão do tema, posteriormente devemos registrar nos documentos norteadores que planejam a política da escola, tais como Plano Pedagógico, Projeto Político Pedagógico de possibilitará o desenvolvimento constante de atividades voltado para esse tema (BRASIL, 2004, [s/d]).

A função social da escola possibilita a compreensão das semelhanças entre os seres humanos e a heterogeneidade que existe em cada um deles, para tanto se faz necessário o desenvolvimento de uma cultura de valorização da diversidade.

Quando se trabalha diversidade no ambiente escolar, é preciso desenvolver antes de tudo, uma convivência harmônica, considerando que todos os envolvidos possuem suas particularidades que devem ser consideradas como parte integrante de sua personalidade, entendendo nossas semelhanças, únicos e por isso, temos as nossas diferenças. O papel da escola na desconstrução do preconceito é:

Conhecer e valorizar a pluralidade étnocultural brasileira; valorizar as várias culturas presentes em nosso país; reconhecer as qualidades de cada cultura, valorizando-as criticamente; repudiar todo tipo de discriminação seja ela de ordem religiosa, étnica, sexual, entre outras; valorizar um convívio pacifico e criativo entre os diferentes; por fim compreender a desigualdade como um problema social passível de mudanças (SOUZA, MOTTA, 2002, p. 46).

Para tanto se faz necessário a implementação de atividades voltadas para essa discussão, com o objetivo de traçar mudanças no cenário escolar reverter o perverso quadro de discriminação racial nas escolas como formação continuada de professores numa perspectiva "afrocentrada"; a retirada de material de conteúdo racista do acervo das escolas e a criação de um núcleo específico na secretaria da educação a fim de trabalhar sobre o assunto do ensino de história afro-brasileira.

Nesse sentido a formação continuada para educadores é fundamental para a construção de consciências voltadas para o entendimento de que somos parte integrantes de uma sociedade que se forma a partir das contribuições pertinentes a luta de todos, que resulta êxitos globais, pois:

È necessário trabalhar a diversidade humana porque é algo fantástico e promissor se for levado em conta a realidade de cada povo e suas 
particularidades para entender toda a imensidão de um grande e múltiplo universo (BRASIL, 2001, p. 19).

Tal abordagem perpassa pela pluralidade cultural, que culmina com discriminação racial, fato que deve ser inserido e abordado nos planejamentos docentes, para garantir a ampliação dos conhecimentos dos agentes constituintes de formação pedagógica. Vale destacar que:

Falar sobre a diversidade cultural e valorizá-la, é trabalhar sobre a superação dos preconceitos, é vencer alguns dos mecanismos de exclusão social, esse trabalho é necessário, porém árduo e insuficiente para chegar ao caminho de uma sociedade igualitária (Ibid., p. 21).

Promover essas discussões nos remete entender que se faz necessário implementar políticas públicas que trabalham contra a discriminação racial, crime, instituído desde 1988 na Constituição Federal. Por outro lado, essas políticas públicas e liberalistas excluem as camadas mais pobres da sociedade e acentuam o preconceito, pois "o grande desafio não é a questão legislativa, mas sim a criação de uma escola que mude a mentalidade das pessoas, já que nela convivem alunos de origens, crenças, culturas e níveis econômicos diferentes" (Ibidem., p. 23).

Nesse sentido, os PCN, fortalecem a promoção de discussões no ambiente escolar com o objetivo na formação de sujeitos críticos e conscientes de seu papel social. É necessário organizar uma estratégia pedagógica voltada para a pluralidade cultural com uma visão interdisciplinar, tendo conteúdos no campo jurídico, de história e geografia, além de estudos populacionais, para construir uma base reflexiva no ambiente escolar.

\section{A Formação Profissional dos Educadores Frente a Implementação da Lei $10.639 / 03$}

A legislação brasileira tem estado atenta à representação de negros (e indígenas) nos materiais didáticos. A questão vem sendo tratada em concordância com as principais tendências do movimento negro, sob dois ângulos: a proibição do racismo em livros e outros materiais didáticos, a exortação à inclusão dos aportes de negros (inclusive da África contemporânea) e indígenas na história e construção do país.

Uma revisão da legislação em vigor, a partir de coletânea organizada por Silva Júnior 2002), permitiu que localizássemos, além dos princípios gerais, reafirmando o 
princípio da igualdade na educação, artigos ou incisos específicos sobre o racismo em livros didáticos em sete Leis Orgânicas Municipais.

Trata-se de prescrição legal aparentemente fácil de ser aprovada, mas dificilmente aplicada, diante dos parcos resultados notados em termos de mudanças. Da forma como tem sido enunciada, não implica uso de recursos, sendo, possivelmente, de fácil negociação, atuando como um carimbo, a baixo custo e investimento governamental, de ação anti-racista (ROMANOWSKI, 2007).

A Lei de Diretrizes e Bases da Educação Nacional (LDB) de 20 de dezembro de 1986 estipula que "O ensino da História do Brasil levará em conta as contribuições das diferentes culturas para a formação do povo brasileiro, especialmente das matrizes indígena, africana e europeia" (Capítulo II, Seção I, Art. 26, § 4º). Mais recentemente, o presidente Luiz Inácio Lula da Silva sancionou a Lei no 10.639 de 9 de janeiro de 2003 que estabelece a obrigatoriedade do ensino da história e cultura afro-brasileira, no ensino fundamental, pois:

\footnotetext{
Políticas de reparação voltadas para a educação dos negros devem oferecer garantias a essa população de ingresso, permanência e sucesso na educação escolar, de valorização do patrimônio histórico-cultural afro brasileiro, de aquisição das competências e dos conhecimentos tidos como indispensáveis para continuidade nos estudos (BRASIL, 2004, [s/p]).
}

É inegável que vivemos dentro da sociedade brasileira um racismo velado manifestado em suas mais diferentes formas. Esse comportamento é refletido no ambiente escolar através de brincadeiras, apelidos e outros comportamentos. Em geral, essa prática é pouco combatida ou sequer percebida pelos educadores, por simplesmente não haver uma preparação adequada.

É de fundamental importância um treinamento e uma reciclagem por parte dos educadores dentro da temática étnico-racial a fim de promover um ambiente democrático e para que se criem mecanismos e procedimentos em que se possa detectar qualquer atitude ou comportamento racista. Atitudes racistas dentro do ambiente escolar podem trazer sérios prejuízos ao processo de aprendizagem por parte de alunos negros, criando um isolamento social e consequentemente dificuldades em seu processo de aprendizagem.

Habilitar os educadores promovendo cursos e treinamentos com ênfase no tema étnico-racial e a inserção desse conteúdo dentro do planejamento didático levando isso para a sala de aula, pode contribuir de contribuir para que de forma 
conjunta educadores e alunos criem uma consciência e mecanismos naturais antiracista (SILVEIRA e NUNES, 2009).

Na perspectiva interdisciplinar cabe um plano diversificado com um cunho que abranja todas as disciplinas, desempenhando particularmente seu papal de formação de cidadãos reflexivos e formadores de opiniões.

As práticas pedagógicas precisam ser desenvolvidas atendendo a implementação da lei 10.639/03 para ampliar os conhecimentos acerca do entendimento da origem dos povos para o melhor entendimento desse cenário. É através do conhecimento da pluralidade cultural, temos a oportunidade de ampliar o entendimento diverso do mundo que nos cerca. É papel do professor desmistificar e intensificar a importância de tratar acerca do preconceito. Entende-se que a diversidade está em nossa volta, pois o conhecimento do outro é oportunidade que nos é dada para perceber e respeitar as diferenças nesse mundo globalizado.

\section{Considerações Finais}

A educação do Brasil foi ajustada numa composição que não considerava todo brasileiro, pois a maior parte da população enxergava-se na maneira contrária a que queria ser vista. Negro ou afrodescendente apresentava a sua parcela como um ser escravizado que desempenhava o trabalho puxado, e perdia a configuração de suas contribuições para o desenvolvimento do estado brasileiro em todos os aspectos.

Com relação a discussão sobre o papel da escola na desconstrução do preconceito e reflexão sobre legislação educacional brasileira para evidenciar o negro como agente ativo pode-se perceber a existência das propostas para a desconstrução do preconceito não obstante das indicações muito bem oferecidas nos temas de "Pluralidade Cultural e Temas Éticos", presentes nos PCN's e na BNCC. É ampla a expectativa de que muitos docentes não consagrem o que esta sendo sugerido nas referidas leis, pois na maioria das vezes esses mesmos docentes, que são responsáveis pelo desenvolvimento de cidadãos críticos, foram vítimas de uma educação preconceituosa e não ganharam instruções adequadas para trabalhar em sala de aula a diversidade cultural, bem como a discriminação racial.

Existe a necessidade de reconhecer as heranças deixadas pelos negros. $O$ Brasil é um país maravilhoso de uma grande diversidade cultural e com um amontoado histórico escondido por trás de falsas crenças, preconceitos e racismos. A diversidade étnica, racial e cultural e a pluralidade de ideias, costumes e fé, formam o nosso 
grande patrimônio e devem se constituir, cada vez mais, como nossa grande riqueza. As pessoas sabem da importância dos negros no processo de formação da identidade brasileira.

Por tudo isso, o modo mais eficaz para minimizar e por que não dizer desenraizar à desigualdade é a reconstrução da história da população negra brasileira a partir do rompimento de barreiras e da quebra de estigmas e estereótipos. Também é fundamental, defender a idéia de um fortalecimento de práticas pedagógicas inclusivas, fornecendo a educadores e agentes sociais novas referências apresentando que o sucesso, a qualidade de vida e as vitórias estão em qualquer contribuindo assim para, a afirmação da auto-estima brasileira, abordando a história e cultura de maneira diferenciada do enfoque tradicional, trazendo à luz a vida deste segmento formador da cultura a partir de um ponto de vista afirmativo.

A discussão sobre o novo fazer educativo depende de uma transformação de atitude pedagógica, de concepção de História e de enfrentamento - começando por uma autocrítica da prática docente como um campo de discussão e reflexão institucionalizado. Nesse prisma, ainda permanece como um ponto amplo de discussão pela relevância dos aspectos que permeiam a profissionalização docente da Educação Básica, Ensino Fundamental e Ensino Médio como: carreira, formação inicial e continuada e os desafios que a categoria enfrenta na sua trajetória.

\section{Referências}

ANDRELINO CAMPOS, A. As Particularidades da Escala de Ação do Movimento Negro: Algumas Considerações sobre a formação do sujeito. São Paulo: Revista Geografares, 2011.

BITTENCOURT, C. (org.). O saber histórico na sala de aula. São Paulo: Contexto, 2004.

BORGES, E. M. F. A Inclusão da História e da Cultura Afro-brasileira e Indígena nos Currículos da Educação Básica. Vassouras: Contexto, 2010.

BRASIL. Ministério da Justiça. Relatório do Comitê Nacional para a Preparação da Participação Brasileira. In: Conferência Mundial das Nações Unidas contra o Racismo, Discriminação Racial, Xenofobia e Intolerância Correlata, 3. Brasília: Ministério da Justiça, 2001.

BRASIL. Ministério da Educação. Secretaria Especial de Políticas de Promoção de Igualdade Racial. Diretrizes Curriculares Nacionais para a Educação das Relações Étnico-Racial e para o Ensino de Historia e Cultura Afro-Brasileira e Africana. Brasília: MEC, 2004. 
CERRI, L. F. Recortes e organizações de conteúdos históricos para a educação básica. Rio de Janeiro: Antíteses, 2009.

CÉLIA DA SILVA, A. Desconstruindo a discriminação do negro no livro didático. Salvador: EDUFBA, 2001.

CHALOUB. S. Visões da liberdade. São Paulo: Companhia das Letras, 1990.

COELHO, W. N. B (Org.). Raça, cor e diferença: a escola e a diversidade. Belo Horizonte: MAZZA, 2008.

EDUCADOR 306. Gestão: racismo na escola. Paraná: EDUC, 2019.

FENELON, D. R. A Formação do Profissional de História e a Realidade do Ensino. São Paulo: Tempos Históricos, 1982.

GOMES, N. L. Escola e diversidade étnico-cultural: um diálogo possível. In: DAYRELL, Juarez (Org.). Múltiplos olhares sobre educação e cultura. Belo Horizonte: UFMG, 1996.

HOBSBAWM, E. Sobre História. São Paulo: Companhia das Letras, 2008.

JESUS, F. S .História e Ensino. Londrina: Contexto, 2012.

ROCHA, L. M. F. A Escola Normal na Província da Bahia. In: ARAUJO, J. C. S.; FREITAS, A. G. B. de; LOPES, A. de P. C. (Orgs). As Escolas Normais no Brasil: do Império à República. Campinas, SP: Editora Alínea, 2008.

ROMANOWSKI, P.J. Formação e Profissionalização docente, Curitiba-PR: Editora Ibpex, 2007.

RODRIGUES, R. N. Os africanos no Brasil. São Paulo: Companhia Editora Nacional, 1935

SANTANA, J. V. J; MORAES, J. O. História do negro na educação: indagações sobre currículo e diversidade cultural. São Paulo: Estud. Econ, 2010.

SCHIMIDT, Maria Auxiliadora. A Formação do Professor de História e o Cotidiano da Sala de Aula. In. BITTENCOURT, C. (org.). O Saber Histórico na Sala de Aula. 7 ed. São Paulo: Contexto, 2002.

SILVEIRA, N.R; NUNES,L.B.I.A. Psicologia da Aprendizagem processos, teorias e contextos. Brasília DF: Liber Livro, 2009.

SOUZA, I. S, MOTTA, F. P. C, FONSECA, D; Estudos sociológicos e antropológicos. São Paulo: Rev .NMH, 2002.

VAINFAS, R. Micro-história: Os protagonistas anônimos da história. Rio de Janeiro: Campus, 2002. 
